\title{
Pneumothorax during laparoscopic surgery
}

\author{
Deepal S Weerasekera ${ }^{1}$, Geetha Kumasinghe ${ }^{1}$, Minary Hewawasam ${ }^{1}$
}

Sri Lanka Journal of Obstetrics and Gynaecology 2010; 32: 67-68

\begin{abstract}
Pneumathorax during laparoscopic surgery is a rare but a life threatening complication. We describe a healthy female who underwent laparoscopy for bilateral endometriotic cysts and developed this complication during the procedure. Awareness of this complication, high degree of suspicion and early treatment is important in avoiding serious consequences in this situation.
\end{abstract}

Key words: pneumothorax, laparoscopy.

\section{Introduction}

Diagnostic and operative laparoscopy is being performed more and more widely in current gynaecological practice. Low morbidity and increased safety of this procedure has contributed to its wide spread use. We describe a rare complication of this procedure which the gynaecologists and anaesthetists should be aware to avoid unexpected disasters ${ }^{1}$. Pneumothorax after laparoscopy is reported as $0.01 \%$ to $0.4 \%^{2}$. If this condition is not detected and treated early it can result in cardiac arrest and even death ${ }^{3}$.

\section{Case report}

39-year old female weighing $57 \mathrm{kgs}$ with bilateral endometriomas was planned for laparoscopic clearance. Her pre-anaesthetic evaluation and investigations were within normal limits. Pre-induction blood pressure was 120/70 $\mathrm{mm} \mathrm{Hg}$ and pulse rate was 78 per minute. Pulse oxymetry and ECG was normal. General anaesthesia was induced with fentanyl 100 micrograms, propofol $120 \mathrm{mg}$ and vecuronium $4 \mathrm{mg}$. Endotracheal intubation was accomplished, and anaesthesia was maintained on intermittent positive pressure ventilation with $\mathrm{O}_{2}, \mathrm{~N}_{2} \mathrm{O}$, isofurane (2 1/ $\min -41 / \mathrm{min}, 1 \%)$.

\footnotetext{
${ }^{1}$ Durdens Hospital, Colombo.

Correspondance: Deepal Weerasekera

E-mail: deepalsenaka@yahoo.co.uk
}

Pneumoperitoneum was created and the patient was put in the lithotomy position. Intra abdominal pressure was maintained between $16-18 \mathrm{mmHg}$. Laparoscopy was performed in steep head down position. During the procedure $\mathrm{O}_{2}$ saturation dropped to $94 \%$ and the $\mathrm{FiO}_{2}$ decreased to $50 \%$. The pneumoperitonium was maintained for approxi-mately 20 minutes. At the end of the procedure patient was reversed with atropine $1.2 \mathrm{mg}$ iv and neostigmine $2.5 \mathrm{mg}$ iv. Patient became conscious but restless. $\mathrm{O}_{2}$ saturation was around $94 \%$ even with $100 \% \mathrm{O}_{2}$. Her $\mathrm{BP}$ was 110/70 $\mathrm{mmHg}$ and the heart rate was around $80 /$ mint. On auscultation air entry was diminished on right side of the chest. Right side pneumothorax was suspected and portable $X$ ray chest was done while patient was on the operating table. This showed a right sided pneumothorax. Patient clinically improved within the next 30 minutes with mask $\mathrm{O}_{2}$. $A$ repeat chest $X$ ray in the recovery showed a marked improvement. Subsequently she was monitored in the intensive care unit. Without any intervention patient became comfortable and $\mathrm{O}_{2}$ saturation increased to $100 \%$. Spontaneous and complete expansion of the lung occurred within about 6 hours and confirmed by repeat chest $X$ ray. She was discharged home on the 3rd day without any further complications.

\section{Discussion}

Exact aetiology of spontaneous pneumothorax during laparoscopy still remains unknown. Various hypotheses include congenital weakness in the diaphragm, oesophageal hiatus and weakness or failure of fusion of the sterna-costal or lumbar part of diaphragm which may disrupt due to pressure of pneumoperitoneum resulting in pneumothora ${ }^{4}$. Leak of $\mathrm{CO}_{2}$ through the oesophageal or aortic hiatus may cause a pneumomediastinum that may rupture in the pleural space causing a spontaneous pneumothorax ${ }^{5}$. In this case the patient was a healthy female without any pre-existing lung disease. During the major part of the procedure she remained haemodynamycally stable, maintaining oxygenation. Signs and symptoms of respiratory distress and hypoxaemia became evident during the later part of the procedure. If the condition is not detected early it can progress to decreased functional residual capacity, increased 
airway pressure, hypercarbia, and circulatory impairment ${ }^{6}$. Careful monitoring and a high index of suspicion in a patient whom ventilation becomes difficult can result in early diagnosis and treatment of this complication. Intermittent positive pressure ventilation might delay the diagnosis but this can be confirmed by a pre-operative $X$ ray. Although our patient improved without any interventional measures, urgent chest decompression becomes necessary in patients who develop tension pneumothorax. Immediate communication between team members, releasing the pneumoperitonium, and reversion of Trendelenberg position to reduce diaphragmatic splinting and needle thoracostomy may be necessary immediately. If the surgery is not completed this may have to be converted to an open procedure. In Sri Lanka laparoscopic surgery is becoming widely popular and therefore surgeons and anaesthetists should be well aware of this complication which can be life threatening although rare.

\section{References}

1. Shah V, Butala B, Parikh B, Raval R, Bilateral pneumothorax as a complication of laparoscopy - a case report. Indian Journal of Anaesthesiology 2003; 47(1): 55.

2. Kumar G, Singh AK. Pneumothorax during laparoscopic cholecystectomy. MedicalJournal of Armed Forces of India 2007; 63: 277.

3. Amarasinghe T. Tension pneumothorax at laparoscopic gynaecological surgery. Sri Lankan Journal of Anaesthesiology 2009; 17(2): 87-9.

4. Prystowsky JB, Jericho JB, Epstein MH. Spontaneous bilateral pneumothorax: complication of laparoscopic cholecystectomy. Surgery 1993; 114: 988-92.

5. Toris JL. Anaesthesia for laparoscopic surgery. In: Miller RD, Fleisher LA, Johns RA. Editors. Miller's Anaesthesia 6th edition, New York: Churchill Livingstone, 2005.

6. Togal T, Gulhas N, Cicek M, Teksan H, Ersoy O. Carbon dioxide pneumothorax during laparoscopic surgery: Surgical Endoscopy 2002; 16: 1242-4. 